\title{
Adenopatía axilar por siliconas: revisión. Algoritmo de estudio y tratamiento.
}

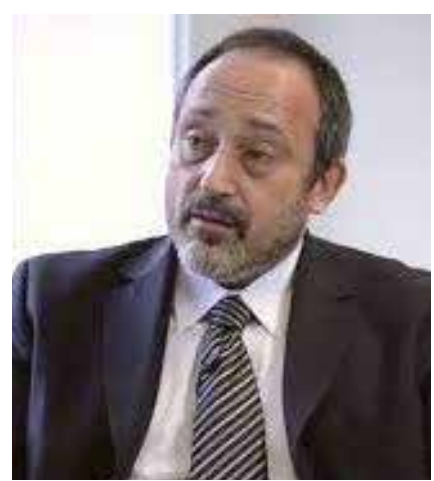

Gustavo Schenone $^{1} \bullet$ Edgardo T. Bernardello ${ }^{2}$ Baltasar Eduardo Lema ${ }^{3}$

1. Doctor en Medicina (UBA). Especialista en Cirugía (MAAC). Especialista Universitario en Cirugía Plástica (UBA). Recertificado SACPER. Docente Autorizado, Facultad de Medicina (UBA). Ex Staff División Cirugía Plástica, Hospital de Clínicas José de San Martín (UBA). SCPBA, FILACP, ISAPS, ASPS. Buenos Aires, Argentina.

2. Profesor Consulto de Mastología, Facultad de Medicina (UBA). Ex Presidente de la Sociedad Argentina de Mastología. Ex Director de la Escuela Argentina de Mastología.

3. Ex Jefe del Servicio de Patología, Hospital Rivadavia. Patólogo del Instituto Argentino de Diagnóstico y Tratamiento. Ex Presidente de la División Argentina, Academia Internacional de Patología. Ex Docente Asociado de Patología, UBA.

\section{"Axillary adenopathy due to silicones: review. Study and treatment algorithm."}

\begin{abstract}
Palabra Clave: Siliconoma axilar, adenopatía axilar, vaciamiento axilar.
Key Words: Silicone, axillary siliconoma, silicone lymphadenopathy, complete axillary lymphadenectomy.
\end{abstract}

\section{RESUMEN}

Introducción. La linfadenopatía por siliconas es un efecto colateral muy raro de la mastoplastia de aumento con implantes o por inyección de siliconas. Es una patología benigna. Los ganglios afectados más frecuentemente, son los axilares. La presencia de una adenopatía axilar unilateral en una paciente adulta siempre debe generar la sospecha de una enfermedad neoplásica, que debe ser estudiada. La magnitud del problema va a depender del grado de infiltración ganglionar, el número de ganglios afectados y la reacción de los tejidos que los rodean. Terapéutica. La decisión respecto al estudio y tratamiento debe hacerse de acuerdo al algoritmo diseñado a tal efecto. Descartar una patología neoplásica mamaria es el primer gesto. Descartada la malignidad, se puede adoptar una conducta expectante $\mathrm{o}$, si fuera necesario, iniciar tratamiento sintomático farmacológico, pero nunca con cirugía en esta etapa. Si a pesar del tratamiento médico persisten las tumoraciones dolorosas, puede procederse a la remoción conservadora de los siliconomas. Si existe afectación del plexo braquial o vascular deben convocarse a neurocirujanos y cirujanos vasculares. Conclusión. La linfadenopatía por siliconas es una complicación rara de los procedimientos que involucran siliconas. Los ganglios linfáticos axilares son los más fre-

\section{ABSTRACT}

Introduction. Lymphadenopathy due to silicone is a very rare side effect of breast enlargement with implants or silicone injection. It is also a benign pathology. The most frequently-affected lymph nodes are axillary lymph nodes. The presence of unilateral axillary adenopathy in an adult patient should always generate the suspicion of neoplastic disease, which must be ruled out. The magnitude of the problem will depend on the degree of lymph node infiltration, the number of affected lymph nodes, and the reaction of the tissues that surround them. Treatment. Decisions pertaining to diagnostic workup and treatment must be made according to an algorithm designed for that purpose. Eliminating a mammary neoplasm is the first step. Once malignancy has been ruled out, expectant management can be adopted or, if necessary, symptomatic treatment with immunomodulators, but never with surgery at this stage. If, despite medical treatment, painful masses persist, the siliconomas can be removed conservatively. If there is involvement of the brachial or vascular plexus, neurosurgeons and vascular surgeons should be called in. Conclusions. Silicone lymphadenopathy is a rare complication of medical interventions involving silicone. The axillary lymph nodes are the most frequently affected. The most important differential diag- 
cuentemente afectados. El diagnóstico diferencial más importante es el origen neoplásico. Recurrir a la biopsia por PAAF o excisional. Se debe evaluar y resolver la fuente de siliconas. Los cuadros sintomáticos deben encararse primero con tratamiento médico. Como principio, siliconas en axila, no es quirúrgico. nosis is neoplasm. Fine needle aspiration or an excisional biopsy is indicated. The source of silicone must be evaluated and removed. Symptomatic patients must initially be treated with medical treatment. In principle, axillary silicone is a non-surgical issue.

Los autores no declaran conflictos de intereses.

\section{INTRODUCCIÓN}

La linfadenopatía por silicona -definida como la presencia de siliconas en un ganglio linfático- es un efecto colateral muy raro de la mastoplastia de aumento con implantes o por inyección de siliconas. Es una patología benigna producida por la migración de siliconas hacia el tejido mamario (sea por rotura del implante o inyectada premeditadamente en la propia glándula) que por vía linfática llega a los ganglios axilares.

Los ganglios afectados más frecuentemente, luego de la mastoplastia con siliconas, son primariamente los axilares; pero se han publicado también en los intramamarios, en la cadena mamaria interna y en los ganglios supraclaviculares. ${ }^{1}$ Otras fuentes de origen menos frecuentes en la migración de las siliconas son las prótesis articulares de la mano, ${ }^{2}$ las temporomandibulares, las de cadera, las genitourinarias, etc. En la axila, fue descrito por primera vez en 1978 por Wintsch, Hausnery Capozzi. ${ }^{3}$

La presencia de siliconas en la axila es una complicación rara que ha sido reportada más frecuentemente luego de cirugías articulares que de cirugías mamarias, sean estas con implantes o inyección de siliconas. ${ }^{4}$

En la actualidad, la linfadenopatía por siliconas se detecta de manera incidental, sin significado clínico, durante un estudio por imágenes de control mamario o en la pieza de mastectomía con disección axilar por carcinoma de mama. También puede presentarse, más raramente, como una adenopatía axilar dolorosa.

Desde el punto de vista patológico, la adenopatía por siliconas es un proceso que, por lo general, involucra uno o más ganglios axilares, pero no todos. En los ganglios afectados, el grado de compromiso también es ampliamente variable, desde mínimo a extenso; $y$, en algunos casos, detectable solo luego de examinar todo el ganglio. Las características citológicas de los granulomas por siliconas provenientes de los implantes de gel son indistinguibles de los provenientes de la inyección de siliconas. $5^{5}$

\section{Diagnóstico de situación}

Durante los últimos cincuenta años, la silicona (di- metilpolisiloxano) se ha convertido en uno de los biomateriales más extensamente utilizados en la medicina moderna. De los dos o tres millones de implantes terapéuticos y cosméticos usados anualmente en los Estados Unidos, un alto porcentaje contienen silicona. ${ }^{6,7}$ Como resultado, las enfermedades relacionadas con las siliconas se están observando con mayor frecuencia.

En 1964 Sternberg y Winer acuñaron el término "siliconoma" para describir las reacciones granulomatosas a cuerpo extraño observadas en los tejidos que habían recibido inyecciones de silicona. ${ }^{8,9}$

Desde su primera descripción, los siliconomas no han sido tratados con gran atención por la bibliografía médica. De hecho, su incidencia y prevalencia en la población de mujeres con implantes mamarios son desconocidas y, durante los años ochenta, la mayoría de los cirujanos los consideraban como un hallazgo incidental con poca o ninguna consecuencia. Probablemente, esto era así porque los granulomas no son una enfermedad per se, son una reacción del tejido generada por partículas o agentes insolubles y centrados alrededor de la actividad de monocitos. ${ }^{10}$

Los siliconomas no son carcinogénicos, por lo que la incidencia de cáncer de mama en estas pacientes debe ser similar a aquellas sin estas formas de aumento mamario. ${ }^{11}$

La industria de dispositivos médicos de silicona ha desarrollado importantes cambios que han reducido significativamente la incidencia y gravedad de las complicaciones. No obstante, aún hoy se espera la rotura de, al menos, el $15 \%$ o más de los implantes mamarios modernos entre el tercero y el décimo año de implantados. ${ }^{12}$ Mientras otros estudios informan una tasa de rotura que oscila entre el $0,3 \%$ y el $77 \% .{ }^{13}$ La calidad de los implantes también afecta su vida útil.

Debe tenerse en mente que la mastoplastia de aumento no es una operación "para toda la vida". ${ }^{14}$

\section{Relevancia clínica de la adenopatía axilar por silicona}

La presencia de una adenopatía axilar clínica unilateral en una paciente adulta joven o mayor siempre debe generar la sospecha clínica de una enfermedad neoplásica primaria o metastásica, que debe ser estudiada.

Una adenopatía axilar unilateral en una mujer puede ser el primer signo de un carcinoma de mama. Aunque este es el pri- 
mer diagnóstico por descartar, la mayoría de las adenopatías en pacientes con implantes mamarios se deben a reacciones a cuerpo extraño. ${ }^{15}$

Los implantes mamarios se utilizan desde principios de los años sesenta. Cada año en miles de mujeres se realizan mastoplastias con implantes con fines de aumento o reconstrucción posmastectomía. A medida que pasa el tiempo, aumenta el riesgo de rotura o perspiración de los implantes.

La tasa de perspiración de los implantes ha sido estimada en 100 ug por año para los implantes viejos. En una publicación, se muestra evidencia histológica del escape de silicona del implante a los doce días de colocado. ${ }^{3}$

Es de esperar que el número de pacientes con adenopatías axilares palpables aumente a través del tiempo. Según Truong y cols., el diagnóstico de siliconomas axilares se realiza en un período de diez a veinte años (promedio 14,3 años) después del aumento mamario. ${ }^{16}$

Ante el evento del compromiso ganglionar axilar por siliconas, la magnitud del problema va a depender del grado de infiltración ganglionar, el número de ganglios afectados y la reacción de los tejidos que los rodean.

A pesar de la reputación de las siliconas de no provocar reacciones tisulares, han sido documentadas reacciones inflamatorias granulomatosas, sinovitis, linfadenopatías, endocarditis, nefropatía por siliconas, granulomas y fibrosis hepáticas, hiperesplenismo, ${ }^{17}$ síndrome de distrés respiratorio y enfermedad adyuvante humana.

Las prótesis mamarias de gel de siliconas producen una leve reacción a cuerpo extraño que resulta en la formación de una cápsula alrededor del implante. Aunque muy raramente, algunos pacientes han tenido importantes reacciones inflamatorias locales y complicaciones por la migración de siliconas hacia la axila, el brazo o la pared abdominal. Una vez que el gel de silicona abandona el elastómero de la prótesis, deja de ser biológicamente inerte $y$, en algunas personas, puede generar profundas reacciones patológicas. ${ }^{18}$

Debe tenerse presente que sobre varios millones de pacientes implantados con diferentes tipos de prótesis con siliconas, las complicaciones son muy raras; la mayoría de las publicaciones aparecen como la descripción de un solo caso.4,16

Durante la década del sesenta, muchos autores estudiaron experimentalmente en varias especies de animales las respuestas locales y sistémicas a la inyección de siliconas líquidas. Demostraron la absorción sistémica de las siliconas y hallaron vacuolas del fluido en células del sistema retículo endotelial en el hígado, el bazo, los ganglios linfáticos, las glándulas adrenales y en los macrófagos. Sin embargo, no quedó clara su to- xicidad. ${ }^{19}$

Ha sido publicado ${ }^{20}$ que, una vez que las siliconas atraviesan la cápsula fibrosa que las rodea, pueden entrar en el sistema retículo endotelial y migrar hacia los ganglios linfáticos axilares, donde pueden producir la misma reacción inflamatoria.

Las partículas de silicona pueden migrar a los tejidos por dos mecanismos diferentes: el primero, luego de la rotura o erosión de la prótesis, y el segundo, a través de una perspiración continua a través de un implante intacto. ${ }^{21}$

Cuando se manifiesta esta perspiración, la silicona puede producir fibrosis y reacciones a cuerpo extraño; especialmente cuando se combina con ciertos ácidos grasos, produce dolor y contracturas.

Una vez que las partículas de silicona han atravesado los confines de la prótesis, pueden dispersarse como cualquier reacción fibrótica a los ganglios linfáticos, a través de los macrófagos del sistema reticuloendotelial por el flujo del sistema linfático.

\section{Migración de la silicona}

A pesar de los grandes avances en la manufactura de las prótesis y equipamiento médico, gotas y partículas de silicona aún se escapan dentro de los tejidos corporales mediante una variedad de formas:

Elastómero de silicona (gomas). Comúnmente utilizadas en implantes de articulaciones metacarpofalángicas en pacientes con artritis reumatoidea. Pueden fragmentarse por estrés mecánico prolongado y liberar pequeñas partículas.

\section{Prótesis mamarias rellenas con gel de siliconas.}

Fenómeno de perspiración, es la difusión de pequeñas gotas del gel a través de la membrana de la pared del continente (que está hecha de elastómero de silicona). Estos nuevos implantes, desarrollados ya hace veinte años, se comercializan afirmando que, gracias a la cohesividad de su gel, este no migrará, aunque su continente se rompa..$^{22}$ En la mayoría de los casos, la silicona es contenida localmente dentro de la cápsula fibrosa periprotésica, pero la migración a distancia ocasionalmente ocurre. La migración al tejido mamario o, más raramente, dentro de la axila, el brazo, el esternón y la ingle se ha descrito y puede estar relacionada con la baja cohesividad del gel, con traumatismos del implante y con las ya proscriptas antiguas maniobras de capsulotomía cerrada. La capsulotomía cerrada es una maniobra de fuerte compresión de la mama y la prótesis con la que se intenta "romper y aflojar" la cápsula fibrosa retráctil periprotésica. Esta maniobra tiene una incidencia del $10 \%$ de complicaciones, inclusive la rotura de la prótesis. La alta presión generada por estas maniobras causa la rotura del implante y la salida de grandes cantidades de gel a presión hacia los tejidos circundantes y distantes, incluidos la axila, la región torácica inferior, la pared abdominal y la región interna 
del brazo. ${ }^{23}$

Pero el gel de silicona se ha documentado que migra desde los implantes mamarios a través de tejidos blandos hacia una gran variedad de sitios: ganglios axilares, fosa antecubital, brazo, tórax, hombro y a través de la pared abdominal hasta la ingle.

Migración linfática. La migración a través de los vasos linfáticos es lenta, le lleva de seis a diez años para llegar desde los implantes mamarios hasta los ganglios linfáticos axilares y de cuatro a ocho años, desde las prótesis metacarpofalángicas. ${ }^{24}$

La presencia de partículas/gotas de silicona y poliuretano relativamente grandes en ganglios linfáticos regionales sugiere que el tránsito de varios elementos, tanto sintéticos como biológicos, desde el tejido mamario hacia los ganglios linfáticos vía canales linfáticos puede tener un significativo componente pasivo. Este componente pasivo puede ser un factor importante en el proceso metastásico. ${ }^{3}$

Migración hematógena. La silicona puede ingresar al torrente circulatorio a través de la fragmentación de partículas de los equipos de circulación extracorpórea (bypass cardiopulmonar, prótesis valvular cardíaca, hemodiálisis) o desde la inyección directa de siliconas en los tejidos. Estas partículas viajan por el torrente circulatorio hasta casi cualquier tejido: hígado, bazo, ganglios linfáticos, riñones, pulmones, cerebro, páncreas, adrenales y medula ósea.

Es importante el tener en mente que la silicona puede migrar hacia lugares distantes al sitio de aplicación.

\section{Perspectiva clínica de la migración}

Nuestra experiencia sobre la incidencia de la linfopatía por siliconas coincide con la de la bibliografía consultada, (menos del $0,01 \%)$. Nalbandian manifiesta que la baja incidencia de complicaciones relativamente menores por reacciones a cuerpo extraño "no constituye una contraindicación para el uso de la silicona como material constitutivo de los implantes". ${ }^{25}$

Las reacciones granulomatosas pueden aparecer como linfadenopatías y, cuando lo hacen en la axila, debe descartarse una neoplasia en la mama ipsilateral.

En 1968, Symmers publica haber encontrado linfadenopatías axilares dolorosas por siliconas en pacientes a quienes les habían inyectado siliconas en las mamas con fines cosméticos. Refiere que al principio las adenopatías remitían. Pero con el paso del tiempo, se hacían permanentes. ${ }^{26}$

\section{Las siliconas en la axila propiamente dicha}

\section{CLÍNICA}

La presencia de siliconas en los ganglios axilares, por lo general, es un hallazgo a través de un control mamográfico de rutina en una paciente asintomática -tanto mamario como axilarque tiene, o bien siliconomas mamarios por inyección o prótesis de siliconas, de las que puede o no conocerse previamente su extravasación.

Muy poco frecuente es que la enferma consulte por molestias indefinidas en la axila y con clínica negativa, y menos aún que lo haga por una tumoración axilar dolorosa, dura y significativa, que enfrenta al mastólogo a diferentes diagnósticos.

Cuando el hallazgo es casual, y por ello asintomático, el especialista debe centrar su atención en la mama.

Si consulta por sintomatología axilar poco clara como sensación de molestias en el hueco axilar o un dolor esporádico de breve duración en determinados movimientos del miembro superior, con axila clínicamente negativa, pero con evidencia de siliconas en algún o algunos ganglios en el estudio por imágenes, el médico debe hacer los diagnósticos diferenciales que correspondan para definir su origen.

Otras veces y ante las mismas circunstancias, el profesional puede palpar uno o dos ganglios no mayores al centímetro, duros y móviles.

En ambas situaciones, una vez confirmado por las imágenes el número de ganglios afectados, lo prudente es contemporizar, explicar a la paciente el real valor del cuadro clínico y centrar la atención en la fuente de migración que seguramente será pasible de la corrección quirúrgica que corresponda.

El abordaje conservador de esta patología es la conducta más favorable, considerando que el hallazgo de adenopatías por silicona generalmente se puede producir incidentalmente durante el vaciamiento axilar por un carcinoma de mamas con implantes íntegros.

La situación más compleja es cuando consultan por una tumoración axilar, por lo general, mayor de $3 \mathrm{~cm}$, fija, dolorosa, que pone al médico ante la disyuntiva de una metástasis de cáncer de mama. La presencia de abundante silicona en la radiología axilar acompañada de una intensa reacción fibrosa orientarán hacia un granuloma por siliconas, que siempre debe ser confirmado por la biopsia percutánea con aguja gruesa ante la posibilidad de una formación oncológica. ${ }^{24,27}$ Esta situación obliga a una conducta cruenta, que se expone en el tratamiento (vide infra).

\section{iMÁGENES}

La radiología de la axila a través de una mamografía pone de manifiesto la sustancia siliconada muy fácil de reconocer. Ella se muestra con una imagen muy densa que contrasta notoriamente con la baja densidad de los tejidos blandos de la axila (Figuras 13.1-13.4).

Por lo general, su cantidad es escasa en no más allá de dos o tres ganglios. Mayor compromiso en cantidad de siliconas o número de ganglios afectados suele acompañarse de sintoma- 
tología clínica como fuera expuesto.

El ultrasonido también es útil en estas circunstancias. Reconoce imágenes muy densas, de bordes regulares con marcada sombra acústica posterior (imagen "en tormenta de nieve" o "televisor descompuesto").

Con los métodos antedichos, es suficiente para hacer el diagnóstico de siliconomas en axila. Se puede recurrir a la resonancia, a la scintimamografía con sestamibi ${ }^{28} 0$ a la ${ }^{18}$ F-FDG PET/TC cuando existen dudas sobre la etiología de la formación axilar. Como lo expresara D'hulst, la ${ }^{18} \mathrm{~F}$-FDG PET/TC ${ }^{29}$ frente a adenitis reactivas por siliconas en los ganglios no es tan específica como la mamografía, pero siempre se debe tener presente una biopsia percutánea ante la duda con metástasis de carcinoma. ${ }^{30}$

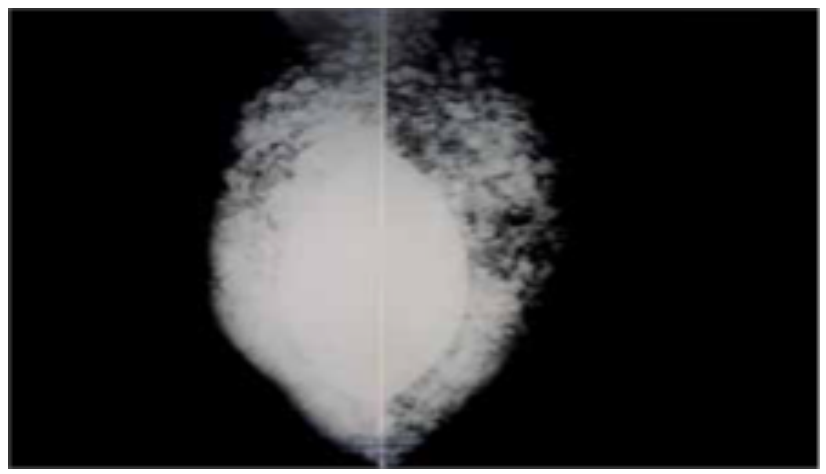

Figura 1.1 Siliconas en la axila. Mamografía con siliconas en la axila. Se observa una mamografía bilateral en oblicua, en mamas con implantes protésicos en que en ambas existe abundante cantidad de siliconas libres quenosoloseesparcenporlamama, sinoquetambiénmigranhacialaaxila ${ }^{31}$

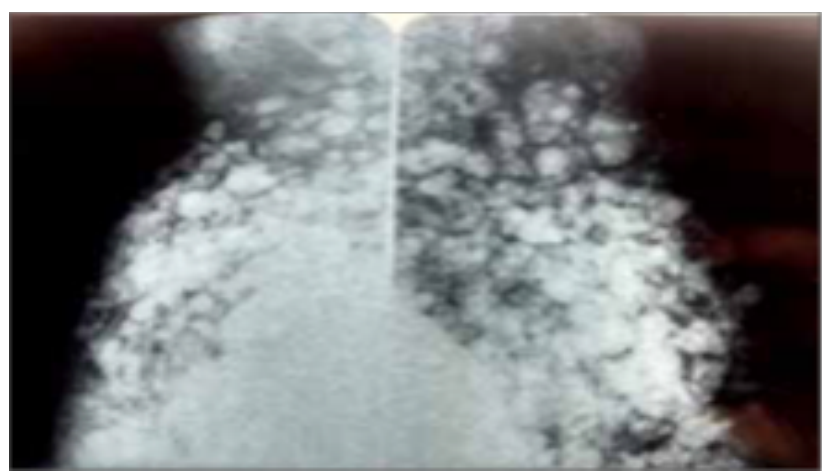

Figura 1.2 Siliconas en la axila. Mamografía con mayor detalle de la región axilar31. Nótese que gran parte de las axilas están ocupadas por siliconas.

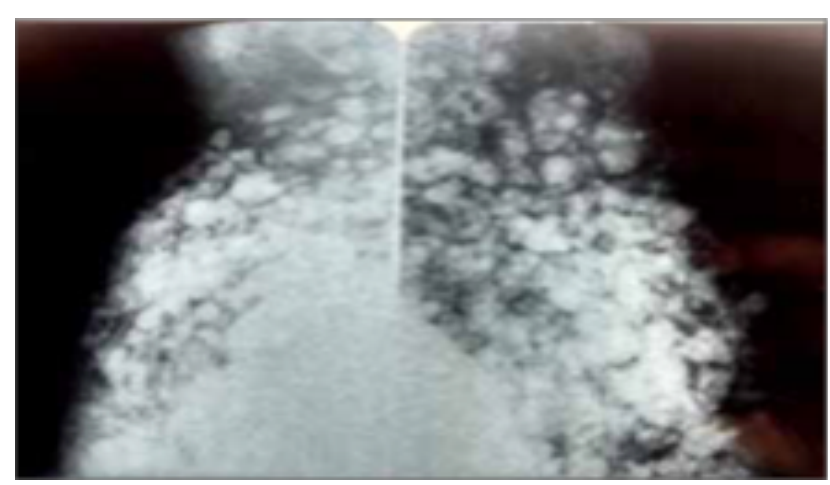

Figura 1.3 Siliconas en la axila. Se muestra la parte baja axilar alcanzada ya por la migración de siliconas ${ }^{31}$.

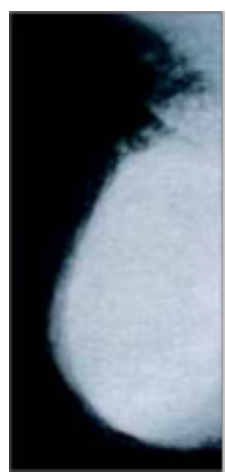

Figura 1.4 Siliconas en la axila. Mamografía. La misma mamografía de la Figura 3, donde, además, se aprecian innumerables opacidades bilaterales producto de la inyección de siliconas ${ }^{31}$.

\section{Patología}

Lesiones ganglionares por siliconas (linfadenopatía granulomatosa por siliconas)

La migración de pequeñas partículas de siliconas por la vía linfática a los ganglios puede producir una linfadenopatía granulomatosa; ;3, 32, 33 los ganglios más frecuentemente afectados son los axilares, pero pueden producirse también migraciones a otros territorios ganglionares como supraclaviculares, mediastinales, etc. ${ }^{34,35}$

La linfadenopatía por siliconas puede dificultar el estudio intraoperatorio del ganglio "centinela" en el caso de una paciente a la que se le había colocado anteriormente una prótesis por razones solamente estéticas y, luego, en el trascurso del tiempo, desarrolló un carcinoma.

Las siliconas en los ganglios se observan, del mismo modo que en los "siliconomas", en forma de pequeños glóbulos o masas de material amorfo birrefringente, especialmente en los senos linfáticos, o como pequeñas vacuolas intracitoplasmáticas en histiocitos de citoplasma microvacuolado (Figuras 1.5 a 1.8) que provocan una reacción granulomatosa en el ganglio; puede haber células gigantes multinucleadas. El tamaño de las lesiones ganglionares puede corresponder desde pequeños focos que respetan la arquitectura ganglionar, sin producir adenomegalia y que constituyen solamente un hallazgo histológico, hasta extensas zonas, con reemplazo de la mayor parte de la estructura ganglionar, con aumento del volumen del ganglio y, ocasionalmente, con rotura de la cápsula ganglionar, infiltración del tejido adiposo periganglionar y la correspondiente reacción granulomatosa periganglionar ${ }^{38}$. 


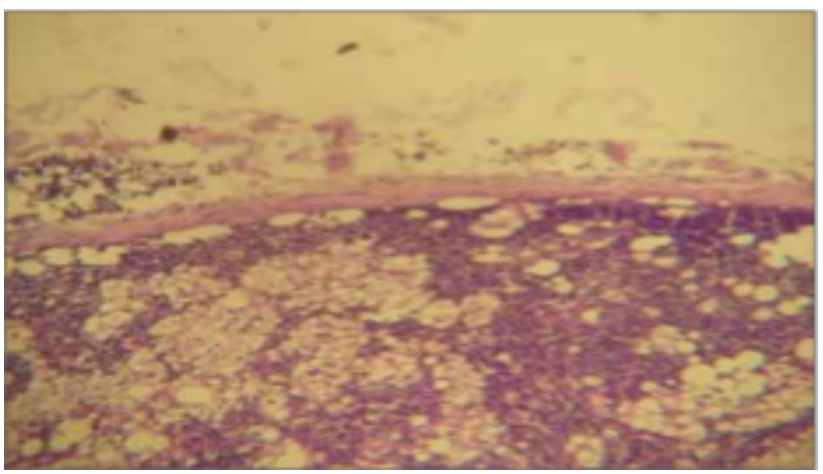

Figura 1.5 Siliconas en la axila. Ganglio con depósitos de siliconas e histiocitos microvacuolados en los senos linfáticos. (100 x).

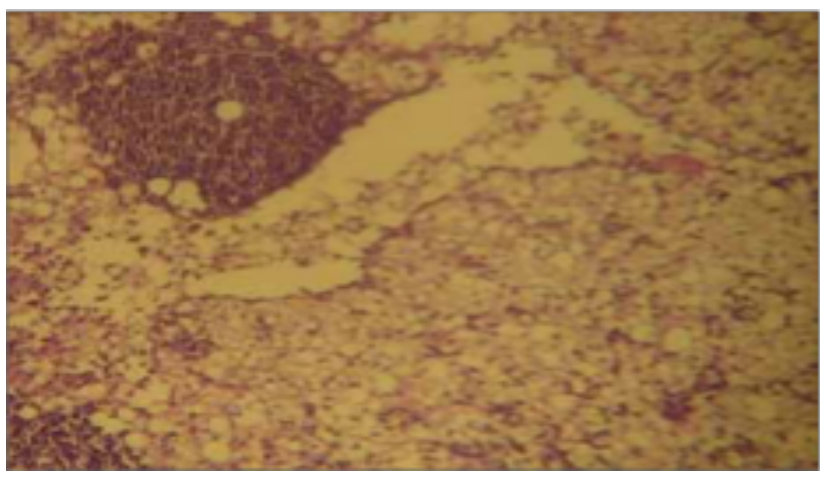

Figura 1.6 Siliconas en la axila. Senos linfáticos ganglionares dilatados con depósitos de silicona e histiocitos microvacuolados. (200 x).

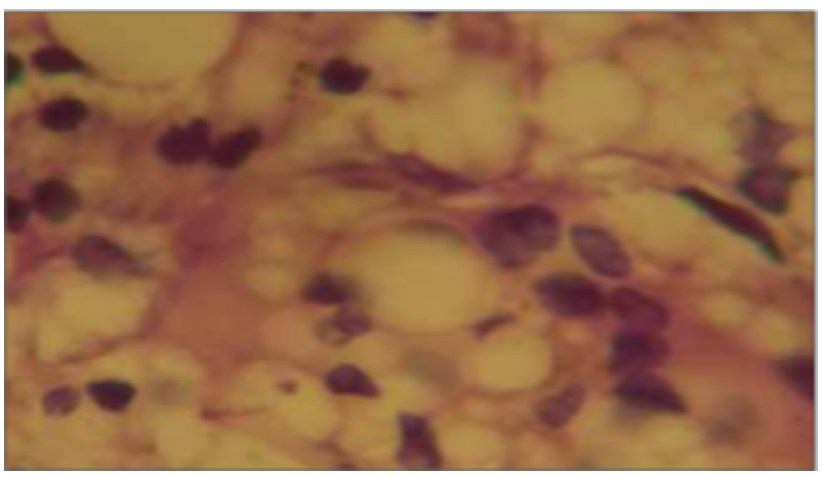

Figura 1.7 Siliconas en la axila. Grumos de siliconas e histiocitos microvacuolados en ganglios. (450 x).

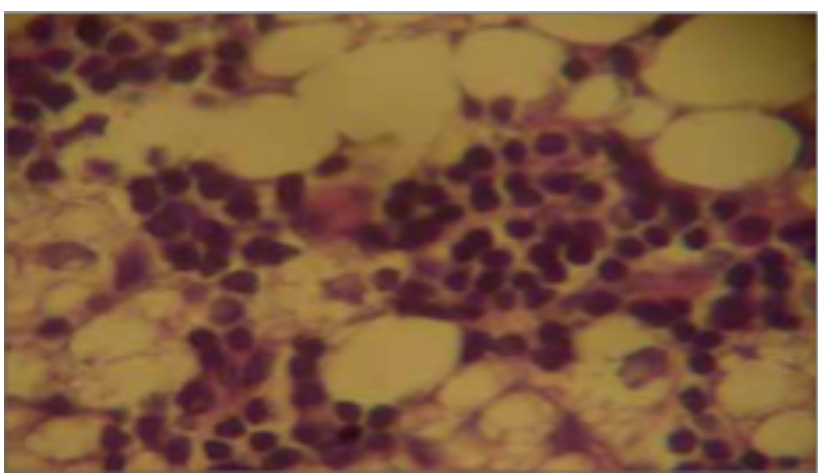

Figura 1.8 Siliconas en la axila. Grumos de siliconas en ganglio. (450 x).

\section{Manejo específico en la axila. Algoritmo}

La decisión respecto al estudio y tratamiento debe adaptarse a cada caso en particulary de acuerdo al algoritmo diseñado a tal efecto (gráfico 1).

De acuerdo a las normas de la bioética, se debe tomar en consideración y respetar los deseos de la paciente, después de haberla informado largamente respecto a las distintas alternativas posibles.

Ante su hallazgo a través de una mamografía que toma la parte baja de la axila, hay que explicarle a la paciente su significado y abocarse a la fuente de origen de la silicona.

La conducta indicada es descartar una patología neoplásica mamaria con una punción aspiración con aguja fina (PAAF). ${ }^{36}$ Una vez descartada la malignidad, se puede adoptar una conducta expectante.

Cuando se produce una reacción inflamatoria del o de los ganglios afectados lo que conlleva a molestias con los movimientos del brazo, con clínica dudosa al palpar la axila, como primera medida debe descartarse la presencia de posibles metástasis a través de una biopsia percutánea (PAAF bajo guía ecográfica). ${ }^{37}$

Si fuera necesario, el tratamiento es sintomático con inmunomoduladores, pero nunca con cirugía en esta etapa -que debe evitarse por sus complicaciones inmediatas (seromas) - 0 alejadas (dolor residual, parestesias en la cara interna del brazo, etc.).

Si la enferma continuara con dolor y tumoraciones en la zona axilar, inclusive con parestesias del territorio del plexo braquial; lo indicado es instaurar un plan de tratamiento médico a cargo de un especialista en inmunología y enfermedades autoinmunes. Probado está su buen resultado en mejorar y hasta hacer desaparecer los síntomas de los granulomas a cuerpo extraño por siliconas. ${ }^{18}$

$\mathrm{Si}$, a pesar del tratamiento médico de por lo menos seis meses, persiste el dolor o bien por manifestación de cancerofobia, puede procederse a la remoción conservadora de los siliconomas. Solamente deben resecarse los ganglios afectados, no más allá. Esta conducta se basa en el hecho de ser una patología autolimitada y benigna. El hecho de tener siliconas en los ganglios axilares per se no es indicación de vaciamiento axilar. Conducta coincidente con la bibliografía consultada.

A pesar de esta remoción quirúrgica conservadora de los ganglios afectados macroscópicamente, puede suceder que tiempo después las siliconas continúen migrando por el sistema linfático y se manifiesten nuevamente. Entonces, debe dejarse transcurrir un año desde la última intervención quirúrgica axilar para permitir el fin del proceso cicatrizal normal en la axila 
y poder evaluar la real magnitud de la situación. El cirujano no debe dejarse arrastrar por la ansiedad de la enferma y volver a intervenir lo que probablemente sea una reacción fibrosa normal cicatricial; lo que conllevaría probablemente a generar un daño mayor innecesario, habida cuenta de la morbilidad que genera un vaciamiento linfático axilar.

Por medio del tratamiento médico, se evita adoptar una conducta riesgosa y con una alta tasa de complicaciones posoperatorias. La posibilidad de complicaciones aumenta exponencialmente en estas pacientes cuya axila ya fue intervenida quirúrgicamente, donde se suma a los granulomas por siliconomas la fibrosis cicatricial posoperatoria normal.

Existe una diferencia importante entre que haya siliconas en los ganglios axilares, a que haya un verdadero tumor por reacción granulomatosa que, después de intentar tratamiento médico, persiste con sintomatología que disminuye la funcionalidad del miembro superior. Nadie puede discutir que si el problema alcanza ese grado de perjuicio, después de una valoración conjunta con neurólogos, neurocirujanos especialistas en nervios periféricos y con cirujanos vasculares, esa axila es quirúrgica, con las recomendaciones que hemos planteado a la paciente, de las cuales el seroma sería la menos importante

La cirugía de la axila por marcado tumor granulomatoso por reacción a las siliconas, es de excepción, pues el cirujano debe encararlo como "vaciamiento axilar", y hasta puede lesionar elementos nobles de tipo vascular o nerviosos englobados en el tumor.

En las circunstancias antedichas, es frecuente no solo la aparición de complicaciones por el vaciamiento axilar, sino también de secuelas, las cuales pueden alcanzar trastornos graves como la "escápula alata" por sección del nervio serrato, la atrofia del músculo dorsal ancho por sección del paquete torácico-dorsal y, hasta en casos extremos, patología neurológica grave por lesión intraoperatoria de ramas del plexo braquial.

Es tan riesgoso el vaciamiento axilar en los casos extremos de tumores por reacción granulomatosa provocada por siliconas en los ganglios que mereció un comentario editorial en la revista Plastic and Reconstructive Surgery de 1977: "En mi experiencia, el área donde los siliconomas tienden a ser inoperables es en la axila, donde pueden formar una masa como cemento alrededor del plexo braquial y los grandes vasos. Es probablemente mejor dejar esto asi y concentrarse en remover lo más posible las masas mamarias". ${ }^{39}$

La presencia de siliconas dentro del nervio es preocupante. A pesar que la silicona líquida es generalmente inerte, ocasionalmente produce una respuesta inflamatoria significativa.

El flujo de silicona desde la prótesis mamaria hacia el brazo se produce a través de las estructuras neurovasculares mayores de la axila, y la exposición de los principales troncos nerviosos a la silicona es probable. No obstante, esta situación es un evento extremadamente raro.

La silicona puede atravesar los diferentes planos de tejidos sanos e infiltrar los nervios. Los mecanismos por los cuales la silicona es nociva para los nervios son la neuropatía compresiva por reacción fibrótica que genera una fibrosis constrictiva y, si la silicona ingresa en el nervio, puede generar efectos degenerativos por la formación de un granuloma intraneural que da como resultado una grave disfunción nerviosa. ${ }^{40}$

Estudios experimentales han mostrado que el gel de siliconas no es directamente neurotóxico, pero sí induce a fibrosis, que puede llegar a ser constrictiva sobre los nervios o vasos involucrados. Esto acentúa hoy día el concepto no quirúrgico de los siliconomas axilares. Si se decide el vaciamiento axilar, tal conducta no debe ser apresurada e injustificada, ${ }^{41}$ debe estar avalada por un equipo multidisciplinario, con un conocimiento amplio por parte de la paciente de las posibles complicaciones intraoperatorias, de las inmediatas y de las secuelas.

Dado que estamos ante una enfermedad benigna, y en el caso de decidir intervenir quirúrgicamente la axila, debe tenerse en mente la técnica axillary reversed mapping, con inyección de azul de metileno en el antebrazo ipsilateral, lo que preserva los ganglios linfáticos teñidos de forma anterógrada para respetar el drenaje linfático del brazo. ${ }^{42}$

\section{CONCLUSIONES}

- La linfadenopatía por siliconas es una complicación rara de los procedimientos que involucran siliconas.

- Los ganglios linfáticos axilares son los más frecuentemente afectados luego de una mastoplastia con siliconas.

- El diagnóstico diferencial más importante es el origen neoplásico.

- La palpación de una adenopatía axilar en mastología obliga a pensar siempre en un ganglio metastásico, aun cuando la paciente sea portadora de prótesis mamaria. Las imágenes axilares que brinda la mamografía orientan a la presencia de siliconas, pero, en ocasiones, es necesario recurrir a la PAAF o aguja gruesa en manos experimentadas. Si estas no son concluyentes debe realizarse biopsia excisional.

- El médico debe evaluar y resolver la fuente de siliconas.

- La sintomatología que pueda acarrear debe encararse primero con tratamiento médico.

- Como principio, siliconas en la axila, no es quirúrgico. 


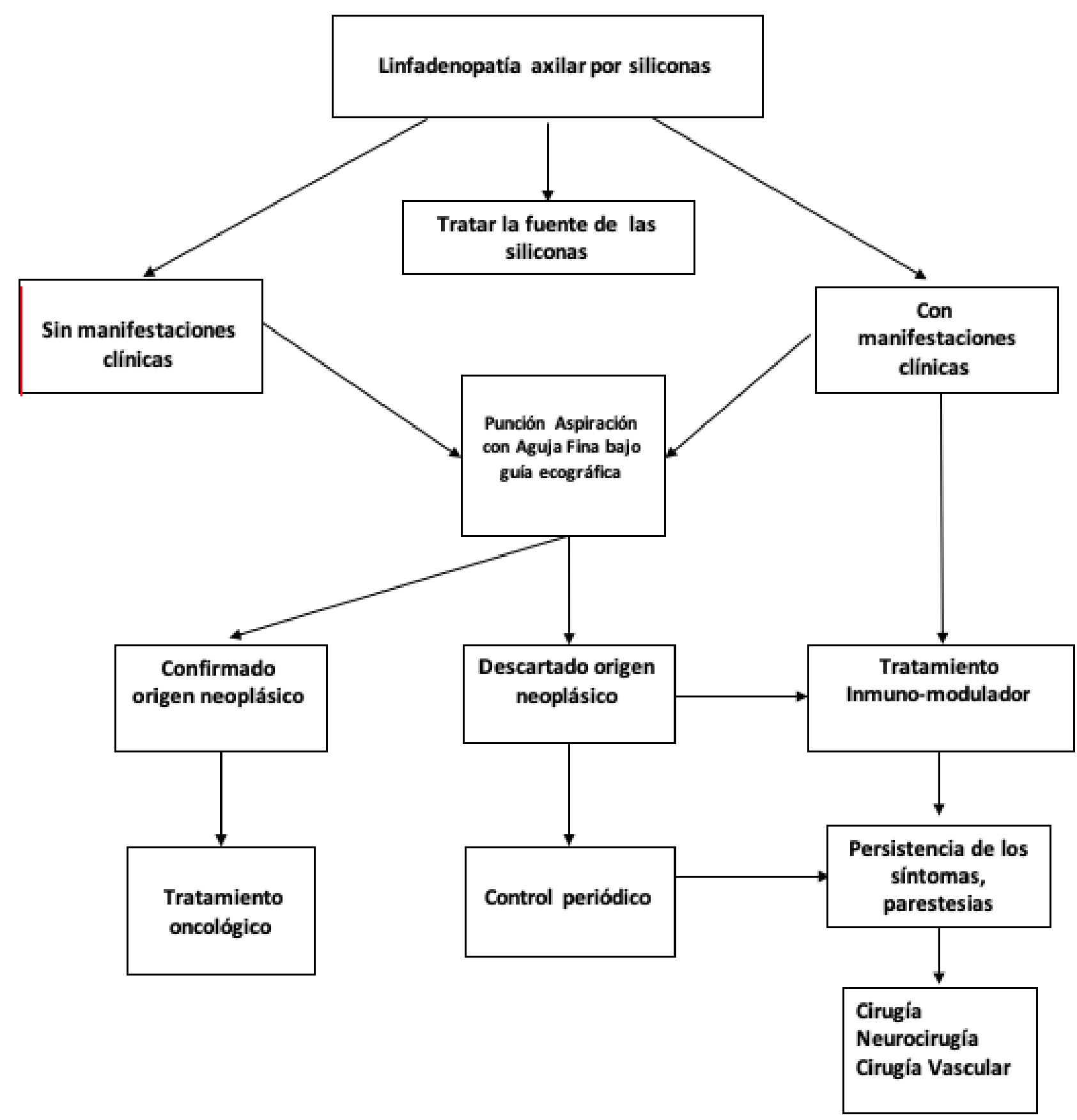

Gráfico 1 Algonitmo terapéutico para adenopatía axilar por siliconas. 


\section{BIBLIOGRAFÍA}

1. Omakobia E, Porter G, Armstrong S, Denton K. Silicone lynphadenopathy: an unexpected cause of neck lumps. JLO 2012; 126: 970-3.

2. Kircher T. Silicone Lynphadenopathy. A Complication of Silicone Elastomer Finger Joint Prostheses. Human Pathology 1980; 11 (3): 240-4.

3. Katzin WE, Centeno JA, Feng LJ, et al. Pathology of lymph nodes from patients with breast implants-A histologic and spectroscopy evaluation. Am J Surg Pathol 2005; 29: 506-11.

4. Adams ST, Cox J, Rao GS. Axillary silicone lymphadenopathy presenting with a lump and altered sensation in the breast: a case report. J Med Case Rep 2009; 10 (3): 6442.

5. Dodd LG Sneige N, Reece GP, Fornage B. Fine-Needle Aspiration Cytology of Silicone Granulomas in the Augmented Breast. Diag Cytopath 1993; 9 (5): 498-502.

6. Travis WD. Silicone Granulomas: Report of three Cases and Review of the Literature. Human Pathology 1985; 16 (1): 19-27.

7. Rivero MA, Schwartz DS, Mies C. Silicone Lynphadenopathy Involving Intramammary Lynph Nodes: A New Complication of Silicone Mammaplasty. AJR 1994; 162: 1089-90.

8. Sternberg TH, et al: Gewebereaktionen auf injizierte ussige silicumverbindungen. Haustarz 1964; 15: 281.

9. Winer $\mathrm{LH}$, et al: Tissue reactions to injected silicone liquids. Arch Dermatol 1964; 90: 588.

10. Austad ED. Breast Implant-Related Silicone Granulomas: The Literature and the Litigation. Plast Reconstr Surg 2002; 109: 1724-9.

11. Nan-jing Peng, et al. Technetium-99m-Sestamibi Scintimammography to Detect Breast Cancer in Patients with Paraffinomas or Siliconomas After Breast Augmentation. Cancer Biotherapy \& Radiopharmaceuticals 2003; $18(4): 573-80$.

12. Lahiri A, Waters R. Locoregional silicone spread after high cohesive gel silicone implant rupture. J Plast Reconstr. Aesth. Surg 2006; 59: 885-6.

13. Khan UD. Left unilateral breast autoinflation and intraprosthetic collection of steril pus: an unusual operative finding of silicone gel bleed with silicone lymphadenitis. Aesth Plast Surg 2008; 32: 684-87.

14. Accurso A, et al. Spread of Silicone tp Axillary linph nodes after High Cohesive Gel Silicone Implant Rupture. Plast. Reconstr. Surg 2008; 122 (6): 221e-222e.

15. Santos-Briz A, López-Ríos F, Santos-Briz A, De Agus- tín PP. Granulomatous Reaction to Silicone in Axillary Lymph Nodes. A case report with Cytologic Findings. Acta Cytologica 1999; 43(6): 1163-5.

16. Truong LD et al. Silicone Lynphadenopathy Associated with Augmentation Mammaplasty. Am J Surg Pathol 1998; 12 (6): 484-91.

17. Zeidan AM, Moliterno AR. Lipogranulomatosis and hypersplenism induced by ruptures silicone breast implants. Blood 2013; 122 (14): 2302.

18. Teuber SS et al. Severe Migratory Granulomatous Reactions to Silicone Gel in 3 Patients. J Rheumatol 1999; 26: 699-704.

19. Ben Hur N. Siliconoma-another cutaneous response to dimethylpolisiloxane. Plast Reconstr Surg 1965; 36: 629.

20. Hausner RJ. Migration of silicone gel to axillary lynph nodes After Prosthetic Mammoplasty. Arch Pathol Lab Med 1981; 105: 371-2.

21. Brody GS. Facts and Fiction about breast implant "bleed". Plast reconstr Surg 1977; 60: 615-6.

22. Shaaban H, Jmor S, Alvi R. Leakage and Silicone lynphadenopathy with cohesive breast implant. BJPS 2003; 56: 518-20.

23. Foster WC. Pseudotumor of the Arm Associated with Rupture of Silicone-Gel Breast Prostheses. J Bone Joint Surg. 1983; 65 (4): 548-51.

24. Paplanus SH, Payne CM. Axillary lynphadenopathy 17 years after digital silicone implants: Study with $\mathrm{x}$-ray microanalysis. J Hand Surg 1988; 13: 411-2.

25. Nalbandian RM. Long-term silicone implant arthroplasty, implications of animal and human autopsy findings. JAMA 1983; 250: 1195.

26. Symmers W. Silicone Mastitis in "Topless" Waitresses and Some Other Varities of Foreign-body Mastitis. Brit Med J 1968; 3: 19-22.

27. Gundeslioglu AO, Hakverdi S, Erdem O, et al. Axillary lipogranuloma mimicking carcinoma metastasis after silicone breast implant rupture: a case report. J Plast Reconstr Aesthet Surg 2013; 66 (3): 72-5.

28. Peng NJ. Technetium-99m-Sestamibi Scintimammography to Detect Breast Cancer in Patients with Parafinnomas or Siliconomas After Breast Augmentation.Cancer Bioth Radioph 2003; 18 (4): 573-80.

29. D'hulst L, Nicolaij D, Beels, Let al. False- Positive Axillary Lymph Nodes Due to Silicone Adenitis on 18F-FDG PET/ CT in an Oncological Setting. J Thorac Oncol 2016; 8: 1-3.

30. Warbrick-Smith J, Cawthorn S. Sentinel Lynph node biopsy following prior augmentation mammaplasty and 
implant rupture. J Plast Reconstr Aesth Surg 2012; 65: 348-50.

31. Schenone GE. Siliconomas mamarios por inyección: clínica, diagnóstico y tratamiento. Buenos Aires: Tesis de Doctorado, Universidad de Buenos Aires, 2008. http:// www.drschenone.com.ar/archivos/ TesisDoctoral.pdf.

32. Rivero MA, Schwartz DS, Mies C. Silicone lymphadenopathy involving intramammary lymph nodes: a new complication of silicone mammaplasty. Am J Roentgenol 1994; 161: 1089-90.

33. Vaamonde R, Cabrera JM, Vaamonde-Martin RJ, et al. Silicone granulomatous lymphadenopathy and siliconomas of the breast. Histol Histopatol 1997; 12: 1003-11.

34. Shipchandler TZ, Lorenz RR, McMahon J,Tubbs R. Supraclavicular lymphadenopathy due to silicone breast implants. Arch Otolaryngol Head Neck Surg 2007; 133: 830-2.

35. Bauer PR, Krajicek BJ, Daniels CE, et al. Silicone breast implant-induced lymphadenopathy:18 cases. Respiratory Medicine CME 2011; 4: 126-30.

36. Tabatowski K. Silicone lymphadenopathy in a patient with mammary prosthesis. Fine needle aspiration cytology, histology and analytical electron microscopy. Acta Cytol 1990; 34: 10-4.

37. Roux SP. Unilateral Axillary Adenopathy Secondary to a Silicone Wrist Implant: Report of a Case Detected at Screening Mammography. Radiology 1996; 198: 345-6.

38. Schenone, GE. Siliconomas mamarios por inyección: clínica, diagnóstico y tratamiento. 1a ed. Buenos Aires: Journal, 2017; 106-116.

39. Management of the Silicone injected breast. Comentario Editorial. Plast Reconstr Surg 1977; 60 (4): 534-8.

40. Sanger RS, Matloub HS. Silicone Gel Infiltration of a Peripheral Nerve and Constrictive Neuropathy following Rupture of a Breast Prosthesis. Plast Reconstr Surg 1992; 89: 949-52.

41. Tehrani H. Axillary lynphadenopathy secondary to tattoo pigment and silicone migration. BJPS 2008; 61 (11): 1381.

42. García MF, Molleda MR. Ganglio linfático axilar infiltrado por silicona procedente de la ruptura de una prótesis mamaria. Cir Esp 2014; 92 (2): 7. 